\title{
POSSIBILIDADE DE ARBITRAGEM NO MERCADO DE CÂMBIO BRASILEIRO
}

\author{
Francisco Carlo da Cunha Cassuce ${ }^{1}$ \\ Carlos André da Silva Muller ${ }^{2}$ \\ Antônio Carvalho Campos ${ }^{3}$
}

\begin{abstract}
Resumo - Este trabalho objetivou determinar a presença de volatilidade nas taxas de câmbio à vista e futura, detectando, assim, a presença de risco. Identificada a presença de volatilidade, procurou-se modelá-la por meio da construção de modelos capazes de prever o comportamento das taxas de câmbio à vista e futura. Os modelos GARCH e TARCH foram usados para modelar a volatilidade das taxas de câmbio. De posse das estimativas, observou-se a existência de convergência dessas taxas na data dos vencimentos dos contratos futuros, identificando-se, assim, a oportunidade de obter ganhos com arbitragem. Os resultados mostraram que as taxas de câmbio futura e à vista são muito voláteis e que o mercado de câmbio à vista apresenta assimetria, sendo mais afetado por impactos negativos. A análise de volatilidade também indicou que os choques nessas taxas perduram por um longo período de tempo. Finalmente, diante das previsões feitas para o comportamento das taxas de câmbio à vista e futura, detectouse a possibilidade de obter ganhos com arbitragem no mercado de câmbio brasileiro.
\end{abstract}

Palavras-chave: arbitragem, taxa de câmbio à vista, taxa de câmbio futura, volatilidade.

\section{Introdução}

O mercado futuro no Brasil vem ganhando importância a cada dia. Billi e Vieira (2005) relatam que o Brasil movimenta mais dinheiro no mercado futuro de câmbio do que os mercados asiáticos e australiano juntos. $\mathrm{O}$ volume financeiro transacionado equivale, anualmente, a nove vezes o PIB brasileiro. Esses autores salientam que o aumento no volume negociado no mercado de câmbio futuro é conseqüência da volatilidade

\footnotetext{
Doutorando em Economia Aplicada pela Universidade Federal de Viçosa. E-mail: fcccassuce@ yahoo.com.br

2 Doutorando em Economia Aplicada pela Universidade Federal de Viçosa.

E-mail: carlos.andre@universidade.net

3 Professor Titular do Departamento de Economia Rural da Universidade Federal de Viçosa.

E-mail: accampos@ufv.br
} 
da taxa de câmbio à vista. Diante dessa flutuação, alguns agentes querem se proteger e buscam contratos de Hedge, enquanto outros aproveitam a volatilidade para auferir lucros. Seriam esses os especuladores e os arbitradores, respectivamente.

Os dois últimos agentes, em especial os arbitradores, atuantes no mercado são o foco desta análise, visto que eles visam obter lucros ou ganhos, operando no mercado futuro, ao passo que o hedger atua no mercado futuro com o objetivo de reduzir os riscos de suas operações no mercado à vista. Assim, por meio do monitoramento das taxas de câmbio à vista $\mathrm{e}$ futura, os especuladores e arbitradores vêm possibilidades de obter lucros, uma vez que detectam condições adequadas para arbitrarem no mercado de câmbio.

Amim (2005), estudando o mercado futuro de cacau, verificou intensa volatilidade no preço desse bem e a possibilidade de praticar arbitragem no mercado dessa commodity. De acordo com BM\&F (2006), práticas de arbitragem seriam, eventualmente, realizadas pelas usinas, entre os mercados de álcool e açúcar, enfatizando que esse procedimento dependerá do poder de manobra das usinas e da disponibilidade de produzir a mercadoria para aquela data futura, levando-se em consideração os impostos que incidem sobre cada produto e os fretes incorridos. Garcia (1997), com base na teoria da paridade coberta da taxa de juros, analisou a possibilidade de obter ganhos com o dólar futuro praticando arbitragem entre mercados. O autor concluiu que, no período de julho de 1994 a maio de 1997, essa prática foi possível. O dólar futuro superestima o dólar à vista no (vencimento do contrato) futuro. Dessa forma, para Garcia (1997), a condição de paridade coberta da taxa de juros foi violada no período considerado. Miguel (2001) afirma que o mercado de câmbio no Brasil não é eficiente, o que poderia provocar erros de estimação das taxas de câmbio à vista e futura. Esses erros abririam brechas para ganhos com arbitragem no mercado de câmbio brasileiro.

É interessante determinar a presença de volatilidade nas taxas de câmbio à vista e futura, detectando, assim, a existência de risco nesses mercados. 
Francisco Carlo da Cunha Cassuce,

Carlos André da Silva Muller \& Antônio Carvalho Campos

A partir daí, procura-se especificar essa volatilidade de forma a desenvolver modelos capazes de melhor prever essas taxas. De posse dessas previsões, detecta-se se ambas as taxas convergiriam na data do vencimento dos contratos futuros, o que possibilita, assim, a prática, ou não, da arbitragem. Assim, este trabalho objetivou verificar a presença de volatilidade nas taxas de câmbio à vista e futura e determinar a existência da possibilidade de arbitragem no mercado de câmbio brasileiro.

A análise compreende o período de 4 de janeiro de 1999 a 15 de dezembro de 2005, totalizando 1.707 observações para o câmbio à vista, e de 2 de janeiro de 2005 a 15 de dezembro de 2005 para o câmbio futuro, totalizando 1.207 observações. Os dados são referentes à taxa de câmbio nominal, real/dólar, para compra e câmbio comercial futuro, com vencimento em $\mathrm{t}+1$, extraídos do site da Bolsa de Mercadorias \& Futuros. As séries utilizadas na análise foram taxa de câmbio à vista e futura para compra, em suas primeiras diferenças.

\section{Referencial Teórico}

Os contratos futuros surgiram como um aprimoramento dos contratos a termo; nestes, as negociações teriam de ser casadas, ou seja, o vendedor de uma determinada mercadoria teria que encontrar um comprador que desejasse essa mercadoria no mesmo prazo estipulado pelo vendedor para entrega e com as devidas características da mercadoria em questão. Dessa forma, os contratos futuros são uma versão moderna dos contratos a termo. No mercado futuro, os contratos são padronizados em termos de qualidade, quantidade, local de entrega e prazos, entre outros, tornando o ativo mais líquido, o que facilita sua negociação em bolsa e reduz consideravelmente os riscos. Essa característica do contrato futuro facilita a especulação, uma vez que os especuladores não têm a intenção de realizar a liquidação física do contrato; em contratos padronizados e com datas de vencimento generalizadas seria muito mais fácil sair de uma posição comprada para posição vendida. 
Para Silva Neto (1998), o mercado futuro só tem sentido a partir do momento em que há riscos no mercado à vista. A partir daí, têm-se três principais participantes neste mercado: os hedgers, os especuladores e os arbitradores. Um exemplo de hedger seria um produtor ou uma empresa utilizando o mercado para se proteger de possíveis alterações no preço de um produto. Sua atividade principal está relacionada com a produção ou o consumo de um produto específico. Para se proteger das oscilações nos preços, esse agente realiza um contrato de venda futura de seu produto. Esse contrato garante-lhe pelo menos um preço que vai possibilitar-lhe obter o lucro desejado. Caso o preço do produto esteja maior na data do vencimento do contrato, o produtor não perde, mas sim deixa de ganhar, tendo seu lucro mínimo garantido (Hull, 1995).

O segundo agente nesse mercado seria o especulador. Esses agentes formam expectativas de preço futuros e, com base nelas, compram e vendem na esperança de obter lucros. Ao contrário dos hedgers, os especuladores não têm como atividade principal a produção ou o consumo das mercadorias negociadas em bolsa. É interessante salientar que o hedger traz o risco de sua posição à vista para o mercado futuro, visto que o especulador toma posição contrária, assumindo, assim, parte do risco do hedger. Em outras palavras, o risco é transferido do hedger para o especulador (Teweles, 1998).

Por último, tem-se o arbitrador. O preço futuro de um produto guarda relação direta com o preço desse produto à vista. Quando essa relação é quebrada, o arbitrador opera em ambos os mercados de modo a obter lucro, até que se restabeleça a relação de preços futuro e à vista.

\section{Possibilidades de Arbitragem}

Teoricamente, os preços futuros e à vista convergem para um mesmo valor à medida que se aproxima o mês de vencimento dos contratos. $\mathrm{Na}$ data do vencimento, preços futuros e à vista se igualam ou ficam bem próximos. 
Francisco Carlo da Cunha Cassuce,

Carlos André da Silva Muller \& Antônio Carvalho Campos

Imagine que o preço futuro esteja acima do preço à vista na data do vencimento. Surge daí a oportunidade de arbitragem. Os operadores vendem contratos futuros, compram o ativo e fazem a entrega, o que faz com que o preço futuro caia. A diferença entre o preço futuro e o preço à vista do ativo determina o lucro da transação. A Figura 1(a) ilustra a situação em que ambos os preços devem convergir.

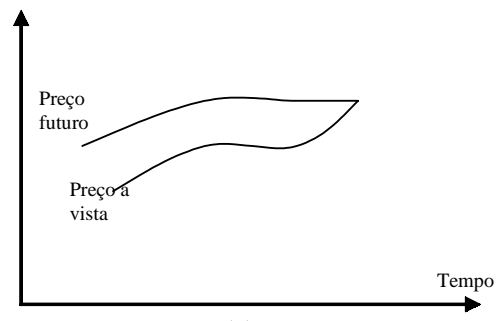

(a)

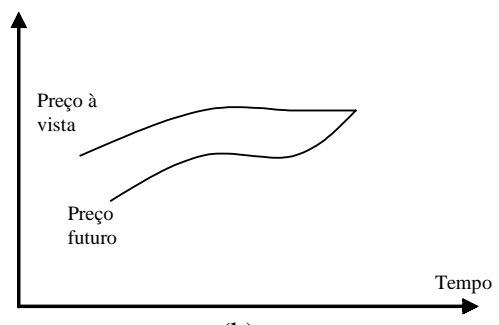

(b)

Figura 1 - Relação entre preço futuro e preço à vista quando se aproxima a data de vencimento - (a) o preço futuro está acima do preço à vista; (b) o preço futuro está abaixo do preço à vista.

Fonte: Adaptado de Hull (1995).

Caso o preço à vista esteja maior do que o preço futuro, os agentes irão comprar um contrato futuro e aguardar a entrega. Com isso, o preço futuro tenderá a subir. $\mathrm{O}$ resultado é que, no longo prazo, os preços futuro e à vista tendem a se igualar. No entanto, Garcia (1997) argumenta que é equivocada a idéia de as cotações do dólar futuro sempre refletirem o valor do dólar à vista, na data do vencimento do contrato. É pouco provável que, na data do vencimento do contrato, as cotações do dólar à vista e futuro convirjam para um mesmo valor. Nesse caso, impostos, diferencial na taxa de juros interna e externa (em caso de negociações entre mercados) e custos de transações (em caso de negociações dentro de um único mercado ou entre mercados) determinam se o diferencial entre as taxas de câmbio futura e à vista seria suficiente para que se possa praticar a arbitragem. 
No estudo em questão, consideram-se os custos de transação como fatores determinantes para a prática da arbitragem. Os mercados de câmbio futuro no Brasil têm vencimentos todos os meses, e o prazo-limite para negociação é o último dia útil do mês anterior ao mês de vencimento. $\mathrm{O}$ valor de cada contrato futuro de câmbio é de US $\$ 50.000,00$, com variação mínima de R $\$ / U S \$ 0,001$. Contudo, não se pode esquecer que os arbitradores incorrem em custos operacionais para realizar essa transação de arbitragem. Segundo dados da BM\&F, as taxas de operacionalização do dólar comercial são de $0,4 \%$ (normal) e $0,2 \%$ (day trade) sobre o valor da operação. Essas taxas devem ser levadas em consideração na hora de determinar se tais operações serão lucrativas ou não.

Os principais agentes no mercado de câmbio pertencem ao setor financeiro, como especificam Garcia e Urban (2004), em especial os bancos comerciais. Para esses autores, operações com arbitragem são um dos principais objetivos do mercado interbancário de câmbio, também conhecido por mercado secundário. Essas operações podem se dar diante do diferencial do preço ou da taxa de juros. A operação de arbitragem mais comum, envolvendo câmbio, é referente à diferença entre a taxa oferecida ao cliente no mercado primário e a taxa do mercado secundário. Os bancos compram ou vendem câmbio aos seus clientes e assumem posições contrárias no mercado secundário, com o intuito de auferir lucros com a diferença entre a taxa oferecida ao cliente e a praticada no mercado no ato da operação.

Outra forma de arbitragem envolvendo taxa de câmbio é a praticada com base no diferencial da taxa de juros entre dois países. Segundo Isard (1995), a depreciação esperada da taxa de câmbio é fundamental na hora de avaliar o retorno esperado de ativos em moedas diferentes. Um ativo medido em reais teria como retorno esperado o rendimento oferecido pela taxa de juros, no período investido. Para compará-lo ao retorno esperado de um ativo em dólares, é preciso conhecer a depreciação esperada da taxa de câmbio real/dólar. 
Francisco Carlo da Cunha Cassuce,

Carlos André da Silva Muller \& Antônio Carvalho Campos

O retorno esperado em reais de uma aplicação feita em dólares seria a taxa de juros do dólar mais a depreciação esperada da taxa de câmbio. Essa idéia é conhecida como paridade descoberta dos juros ${ }^{4}$. Se a diferença entre a taxa de juros doméstica e a taxa de juros externa somada à depreciação esperada do câmbio for positiva, tudo o mais constante, $\mathrm{o}$ banco contrata um empréstimo no exterior, vendendo os dólares no mercado interbancário e aplicando os reais auferidos com a venda deles. O retorno obtido pelo diferencial da taxa de juros contabiliza o lucro da operação, realizada sem qualquer presença de risco. Haverá demanda maior do que a oferta por depósitos em reais e movimento contrário relacionado com os depósitos em dólares. Dessa forma, o real tende a se valorizar em relação ao dólar e a taxa de câmbio tende a cair, elevando o rendimento dos depósitos em dólares. Apenas quando as taxas de rendimento esperadas forem iguais, não haverá excedente de oferta nem de demanda de algum dos depósitos e a paridade de juros é mantida.

O próprio mercado de câmbio se encarrega de eliminar a possibilidade de ganhos com arbitragem, através da desvalorização esperada da taxa de câmbio ${ }^{5}$, de modo que os agentes devem estar sempre atentos para auferirem lucros, sem correr qualquer tipo de risco, praticando arbitragem.

\section{Modelo Empírico}

Os modelos mais adequados para expressar e prever a volatilidade de séries temporais são os de heterocedasticidade condicional, dentre os quais se destacam os modelos ARCH (Modelo Auto-regressivo de Heterocedasticidade Condicional) e GARCH (Modelo Auto-regressivo de Heterocedasticidade Condicional Generalizado). A previsão da volatilidade, ou variância, nos modelos $\mathrm{ARCH}$ é feita com base na volatilidade passada e por um nível médio de volatilidade.

\footnotetext{
Para mais detalhes, ver Isard (1995), Mark (2001) e Krugman e Obstefeld (2005).

Isard (1995) e Mark (2001) salientam que, sob as hipóteses de expectativas racionais e de neutralidade ao risco, a depreciação esperada da taxa de câmbio é equivalente ao prêmio futuro do câmbio, que é a diferença entre a taxa de câmbio futura e a taxa à vista.
} 
$Y_{t}=F(\bullet)+\varepsilon_{t}$

$V\left(\varepsilon_{t}\right)=\sigma_{t}^{2}=\alpha_{0}+\alpha_{1} \varepsilon_{t-1}^{2}+\cdots+\alpha_{n} \varepsilon_{t-m}^{2}$

Na equação (1), $F(\bullet)$ é uma função qualquer (pode ser uma função do tipo ARMA, SARIMA, ou mesmo uma regressão múltipla convencional) e ${ }_{t}$ é o resíduo dessa regressão. A equação (2) mostra que a variância, ou volatilidade, da série taxa de câmbio à vista é dada pela soma dos quadrados dos resíduos defasados.

Assim como os modelos ARCH, os modelos GARCH buscam modelar a variância da série, com a vantagem de serem mais parcimoniosos. Nestes, a volatilidade é dada por um nível médio de volatilidade, $\alpha_{0}$, pela volatilidade observada em períodos passados $\left(\varepsilon_{t-1}, \cdots \varepsilon_{t-m}\right)$ e por previsões passadas da variância $\left(\sigma_{t-1}^{2} \cdots \sigma_{t-r}^{2}\right)$. A equação (3) mostra a volatilidade modelada através de um modelo GARCH.

$V\left(\varepsilon_{t}\right)=\sigma_{t}^{2}=\alpha_{0}+\alpha_{1} \varepsilon_{t-1}^{2}+\cdots+\alpha_{n} \varepsilon_{t-m}^{2}+\beta_{1} \sigma_{t-1}^{2}+\cdots+\beta_{r} \sigma_{t-r}^{2}$

Segundo Mol et al. (2005), a volatilidade pode apresentar assimetria, ou seja, choques negativos podem exercer influência maior do que choques positivos sobre a volatilidade e vice-versa, o que é conhecido por alavancagem. Para captar essa assimetria, modelos TARCH, que pertencem à família GARCH, são os mais utilizados. Tal modelo considera que a volatilidade é determinada pelos mesmos fatores discutidos para o modelo GARCH, mais um termo que determinaria a assimetria da volatilidade $\left(\varepsilon_{t-1} d_{t}\right)$. A equação (4) mostra a previsão da volatilidade considerando um modelo TARCH de assimetria. 
Francisco Carlo da Cunha Cassuce,

Carlos André da Silva Muller \& Antônio Carvalho Campos

$V\left(\varepsilon_{t}\right)=\sigma_{t}^{2}=\alpha_{0}+\alpha_{1} \varepsilon_{t-1}^{2}+\cdots+\alpha_{n} \varepsilon_{t-m}^{2}+\gamma \varepsilon_{t-1}^{2} d_{t}+\beta_{1} \sigma_{t-1}^{2}+\cdots+\beta_{r} \sigma_{t-r}^{2}$

Caso $\gamma$ seja significativo, é identificada a presença de assimetria na volatilidade. Admitindo que $d_{t}=1$, se $\varepsilon_{t}<0$, como choques negativos, e $d_{t}=0$, se $\varepsilon_{t}>0$, para choques positivos, o efeito de $\varepsilon_{t-1}^{2}$ será $\alpha$ para choques positivos e $\alpha+\gamma$ para choques negativos.

\section{Resultados e Discussão}

A análise inicia-se por meio da visualização gráfica das séries de taxas de câmbio para compra à vista e futura, assim como suas respectivas primeiras diferenças, na tentativa de identificar um comportamento volátil. As séries de câmbio para compra à vista e futura, assim como suas primeiras diferenças, apresentam, aparentemente, um comportamento volátil. Contudo, a análise gráfica não é suficiente para detectar a presença de heterocedasticidade ou volatilidade da série, sendo necessário determinar modelos de heterocedasticidade condicional auto-regressiva generalizados (Figuras 2 e 3).

Na construção de modelos da família GARCH deve-se, inicialmente, especificar uma equação genérica (a função $F(\bullet)$ da equação (1)). Essa equação foi especificada como um modelo de séries temporais do tipo ARIMA (p,d,q). O objetivo de se especificar tal modelo é tornar os resíduos não-correlacionados com média zero. Foram utilizadas as séries das primeiras diferenças do câmbio à vista para compra e do câmbio futuro, especificadas anteriormente, que são estacionárias, indicando que "d" é zero. Segundo Lamonier (2000), a escolha desses modelos pode ser feita por meio da análise da Função de Autocorrelação (FAC) e Função de Autocorrelação Parcial (FACP), apresentadas nas Figuras 4, 5, 6 e 7. Vale ressaltar que os dados utilizados, a partir de agora, para determinar os modelos mais adequados excluem as últimas 30 observações em cada série. 


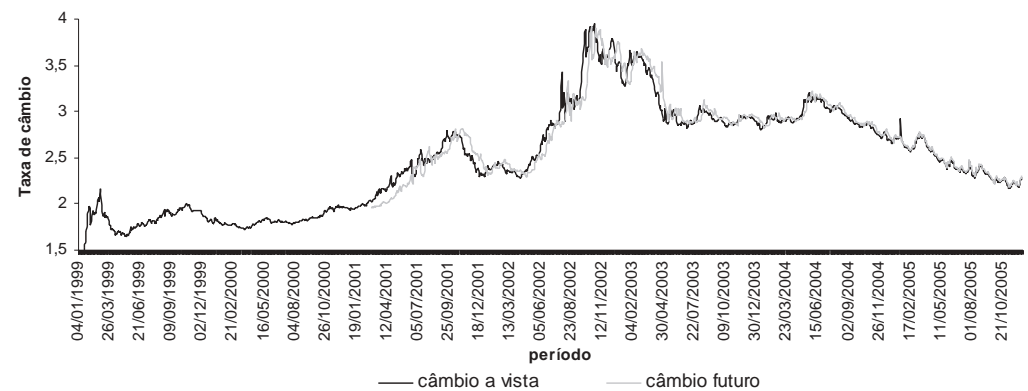

Figura 2 - Câmbio à vista para compra e câmbio futuro.

Fonte: $\mathrm{BM} \& \mathrm{~F}$.

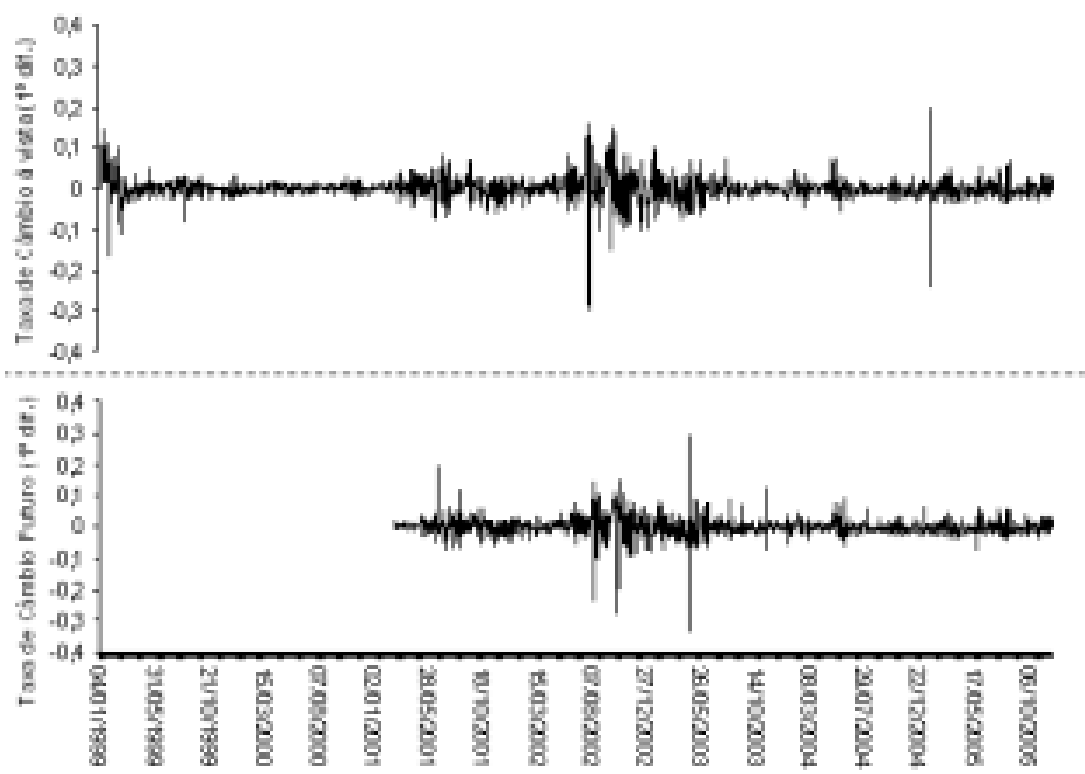

\section{Período}

Figura 3 - Câmbio à vista para compra e futuro diferenciado uma vez. Fonte: Calculado pelos autores com base em BM\&F. 
Como se pode observar nas Figuras 4 e 5, o comportamento da FAC e da FACP da série de câmbio à vista na primeira diferença é de queda exponencial ou na forma de senóide amortecida nos lags iniciais, comportamento semelhante para a FAC e a FACP da série de câmbio futuro, indicando um modelo $\operatorname{ARMA}(\mathrm{p}, \mathrm{q})$.

A ordem do modelo $\operatorname{ARMA}(p, q)$ não pode ser determinada de forma exata. O procedimento indicado é estimar diferentes configurações do modelo ARMA, selecionando os que melhores resultados apresentam para a formação de um modelo GARCH.

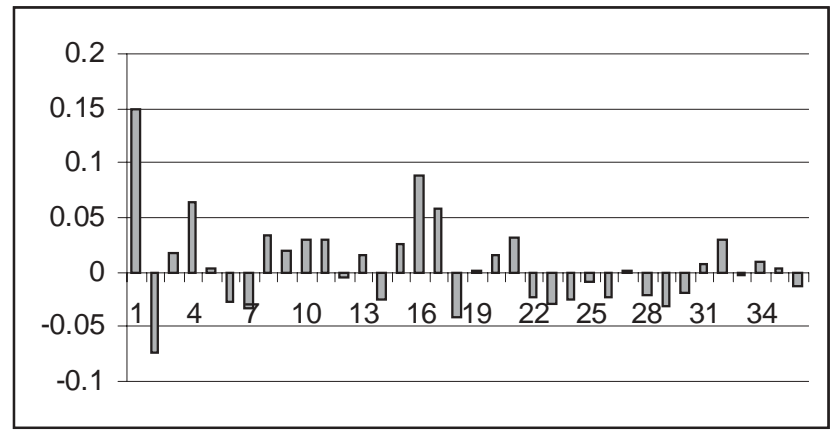

Figura 4 - FAC da série de câmbio à vista na primeira diferença. Fonte: Dados do trabalho.

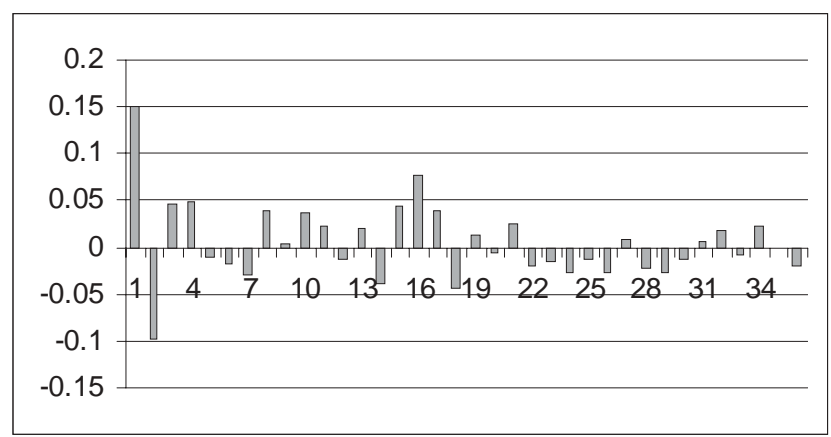

Figura 5 - FACP da série de câmbio à vista na primeira diferença. Fonte: Dados do trabalho. 


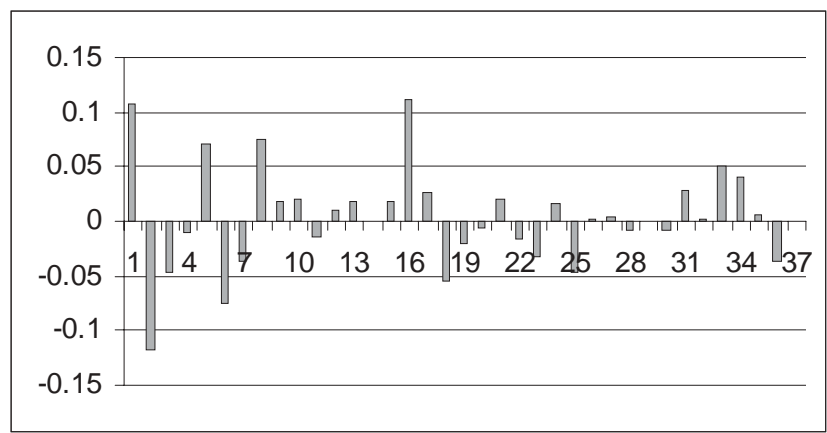

Figura 6 - FAC da série de câmbio futuro na primeira diferença. Fonte: Dados do trabalho.

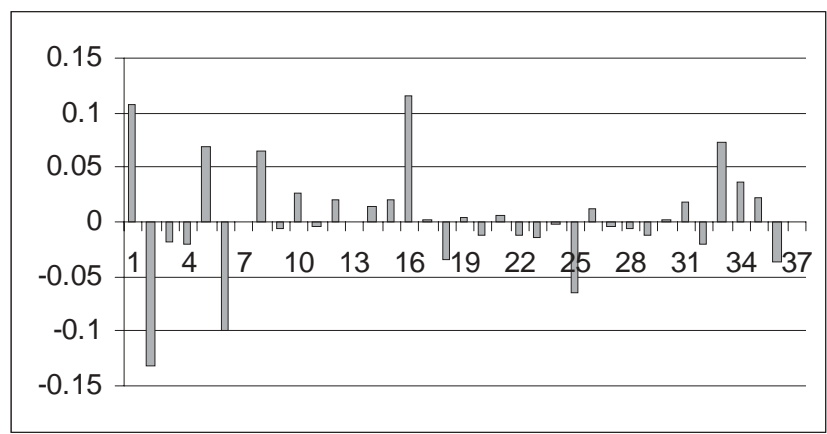

Figura 7 - FACP da série de câmbio futuro na primeira diferença. Fonte: Dados do trabalho.

Com base no procedimento descrito anteriormente, foram estimados dois modelos ARMA — $\operatorname{ARMA}(1,1)$ e $\operatorname{ARMA}(2,2)$ — tomando como base as funções de autocorrelação e autocorrelação parcial de ambas as séries em diferença. As Tabelas 1 e 2 apresentam os modelos $\operatorname{ARCH}(1,1)$, que foram os que melhor se ajustaram, assim como o Akaike Criteria Information (AIB) e Schwartz Baesyan Criteria (SBC). 
Francisco Carlo da Cunha Cassuce,

Carlos André da Silva Muller \& Antonio Carvalho Campos

Tabela 1 - Modelo ARMA(1,1) para câmbio à vista

\begin{tabular}{cccccc}
\hline DTx & Const. & DTx(-1) & $\mu(-1)$ & AIC & SBC \\
\hline 1 & 0,0006 & $-0,26439$ & 0,43716 & $-4,25780$ & $-4,24827$ \\
& $(0,4209)$ & $(0,0000)$ & $(0,0000)$ & & \\
\hline
\end{tabular}

Nota: Os valores em parênteses são os p-valor.

Fonte: Dados do trabalho.

Tabela 2 - Modelo ARMA(1,1) para câmbio futuro

\begin{tabular}{cccccc}
\hline DTx & Const. & DTx(-1) & $\mu(-1)$ & AIC & SBC \\
\hline 1 & 0,0002 & $-0,52834$ & 0,66490 & $-3,93452$ & $-3,92157$ \\
& $(0,8032)$ & $(0,0000)$ & $(0,0000)$ & & \\
\hline
\end{tabular}

Nota: Os valores em parênteses são os p-valor.

Fonte: Dados do trabalho.

A opção por um modelo segue o critério da parcimônia. Entretanto, realizase uma análise mais detalhada para verificar quais desses modelos apresentam resíduos não-correlacionados. Os resíduos de ambos os modelos, para as duas variáveis, mostraram-se não-correlacionados. Contudo, os modelos ARMA(2,2) foram superidentificados, ou seja, os coeficientes de segunda ordem do AR e do MA não foram significativos. A Tabela 3 mostra o teste Q, para um grupo de autocorrelações, de Box e Pierce, cuja hipótese nula é de ausência de autocorrelação.

Resta analisar o comportamento da variância dos resíduos dos modelos ARMA(1,1), com o objetivo de detectar a presença de heterocedasticidade condicional auto-regressiva, ou seja, verificar se apresenta um padrão de comportamento do tipo GARCH. O teste do multiplicador de Lagrange, que testa a hipótese nula de não-correlação das variâncias, foi utilizado para confirmação da presença de heterocedasticidade. $\mathrm{O}$ teste consiste em tomar o $\mathrm{R}^{2}$ da equação $\sigma_{t}^{2}=\alpha_{0}+\alpha_{1} \varepsilon_{t-1}^{2}+\cdots+\alpha_{n} \varepsilon_{t-n}^{2}$ e multiplicá-lo pelo número de observações. Tal teste é apresentado nas Tabelas 4 e 5. Caso um dos parâmetros dessa equação seja significativo, tem-se que a variância (volatilidade) dos resíduos do ARMA(1,1) apresenta comportamento do tipo GARCH. 
Tabela 3 - Teste Q de Box e Pierce para autocorrelação de todos os erros dos modelos estimados

\begin{tabular}{cc}
\hline Modelos & Valor do teste Q \\
\hline ARMA(1,1) para câmbio à vista & $50,63461^{\mathrm{ns}}$ \\
ARMA(2,2) para câmbio à vista & $43,84500^{\mathrm{ns}}$ \\
ARMA(1,1) para câmbio futuro & $51,75387^{\mathrm{ns}}$ \\
ARMA(2,2) para câmbio futuro & $46,01835^{\mathrm{ns}}$ \\
\hline
\end{tabular}

ns - não-significativo.

Fonte: Dados do trabalho.

Como pode ser observado, a estatística do multiplicador de Lagrange confirma, para todas as defasagens, que os resíduos dos modelos $\operatorname{ARMA}(1,1)$ apresentam comportamento do tipo GARCH, ou seja, possuem heterocedasticidade condicional.

Tabela 4 - Resultado do teste do multiplicador de Lagrange para os resíduos do modelo $\operatorname{ARMA}(1,1)$ taxa de câmbio à vista

\begin{tabular}{ccc}
\hline Defasagens do $\varepsilon^{2}$ & Estatística F & $\mathrm{R}^{2 *}$ observações \\
\hline 1 & $280,3591^{*}$ & $241,2088^{*}$ \\
3 & $117,4490^{*}$ & $292,8039^{*}$ \\
5 & $75,99616^{*}$ & $311,8240^{*}$ \\
9 & $44,49915^{*}$ & $325,9323^{*}$ \\
12 & $33,71827^{*}$ & $329,0060^{*}$ \\
\hline
\end{tabular}

"- significativo a $1 \%$.

Fonte: Dados do trabalho.

Tabela 5 - Resultado do teste do multiplicador de Lagrange para os resíduos do modelo $\operatorname{ARMA}(1,1)$ taxa de câmbio futura

\begin{tabular}{ccc}
\hline Defasagens do $\varepsilon^{2}$ & Estatística $\mathrm{F}$ & $\mathrm{R}^{2 *}$ observações \\
\hline 1 & $159,1902^{*}$ & $140,3926^{*}$ \\
3 & $53,79424^{*}$ & $142,2770^{*}$ \\
5 & $32,70068^{*}$ & $144,1043^{*}$ \\
9 & $18,83568^{*}$ & $149,1199^{*}$ \\
12 & $14,14427^{*}$ & $149,5740^{*}$ \\
\hline
\end{tabular}

"- significativo a $1 \%$.

Fonte: Dados do trabalho. 
Francisco Carlo da Cunha Cassuce,

Carlos André da Silva Muller \& Antônio Carvalho Campos

Confirmada a presença de heterocedasticidade condicional, resta determinar a ordem dos modelos GARCH. Antes, faz-se necessário verificar se os erros são distribuídos normalmente, pois os modelos GARCH são estimados por Máxima Verossimilhança. Para isso, aplicase o teste de Jarque-Bera, que indica se a hipótese de normalidade dos resíduos deve ser rejeitada. Os valores da estatística Jarque-Berra são: 17.366,18 para a série de taxa de câmbio à vista e 28.714,51 para a série de taxa de câmbio futura, ambos significativos a $1 \%$. Assim, o teste Jarque-Bera rejeita a hipótese de normalidade dos erros em ambos os casos. Dessa forma, para os modelos GARCH estimados neste trabalho deve-se adotar a opção de Covariâncias Consistentes de Heterocedasticidade ${ }^{6}$.

Com base nos valores do correlograma dos resíduos ao quadrado, dos modelos ARMA(1,1), uma possível especificação para um modelo de heterocedasticidade condicional seria um $\mathrm{ARCH}(4)$ para a taxa de câmbio à vista e um $\mathrm{ARCH}(1)$ para a taxa de câmbio futura. Os resultados (Tabelas 6 e 7) mostram que todos os coeficientes são significativos, o que indica que estes modelos são satisfatórios para modelar a variância das taxas de câmbio à vista e futura. Contudo, ele peca por não ser parcimonioso, especificamente para o modelo de taxa de câmbio à vista.

Tabela 6 - Equação da variância da série de taxa de câmbio à vista na primeira diferença (modelo $\mathrm{ARCH}(4)$ )

\begin{tabular}{cccccc}
\hline & Constante & $\varepsilon_{t-1}^{2}$ & $\varepsilon_{t-2}^{2}$ & $\varepsilon_{t-3}^{2}$ & $\varepsilon_{t-4}^{2}$ \\
\hline & 0,0001 & 0,1961 & 0,2395 & 0,4262 & 0,0857 \\
& $(0,0000)$ & $(0,0116)$ & $(0,0030)$ & $(0,0109)$ & $(0,0702)$ \\
AIC & $-4,845550$ & & & & \\
SBC & $-4,820152$ & & & & \\
\hline
\end{tabular}

Nota: Os valores em parênteses são os p-valor.

Fonte: Dados do trabalho.

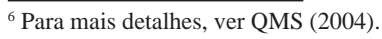


Tabela 7 - Equação da variância da série de taxa de câmbio futura na primeira diferença (modelo $\mathrm{ARCH}(1)$ )

\begin{tabular}{ccc}
\hline & Constante & $\varepsilon_{t-1}^{2}$ \\
\hline & 0,0004 & 0,8218 \\
AIC & $(0,0000)$ & $(0,0000)$ \\
SBC & $-4,310417$ & \\
\hline
\end{tabular}

Nota: Os valores em parênteses são os p-valor.

Fonte: Dados do trabalho.

Outras especificações para modelagem da volatilidade são os modelos GARCH e TARCH. Nos primeiros, a previsão da variância é dada por um nível médio de volatilidade de longo prazo, pela volatilidade observada em períodos passados e por previsões passadas da variância. Os modelos TARCH verificam a existência de assimetria na volatilidade. Ambos os modelos são mais parcimoniosos que os modelos ARCH. Assim, foram estimados modelos $\operatorname{GARCH}(1,1)$ e TARCH$(1,1)$ para taxas de câmbio à vista e futura. Estes modelos são apresentados nas Tabelas 9 e 10.

Tabela 9 - Equação da variância da série de taxa de câmbio à vista na primeira diferença (modelo $\operatorname{GARCH}(1,1)$ )

\begin{tabular}{cccc}
\hline & Constante & $\varepsilon_{t-1}^{2}$ & $\sigma_{t-1}^{2}$ \\
\hline & 0,000009 & 0,15529 & 0,845172 \\
AIC & $(0,0009)$ & $(0,0002)$ & $(0,0000)$ \\
SBC & $-4,905919$ & & \\
\hline
\end{tabular}

Nota: Os valores em parênteses são os p-valor.

Fonte: Dados do trabalho. 
Francisco Carlo da Cunha Cassuce,

Carlos André da Silva Muller \& Antônio Carvalho Campos

Tabela 10 - Equação da variância da série de taxa de câmbio futura na primeira diferença (modelo GARCH $(1,1)$ )

\begin{tabular}{cccc}
\hline & Constante & $\varepsilon_{t-1}^{2}$ & $\sigma_{t-1}^{2}$ \\
\hline & 0,00005 & 0,320596 & 0,676896 \\
AIC & $(0,0175)$ & $(0,0000)$ & $(0,0000)$ \\
SBC & $-4,483776$ & & \\
\hline
\end{tabular}

Nota: Os valores em parênteses são os p-valor.

Fonte: Dados do trabalho.

Os modelos GARCH(1,1) apresentam ótimos resultados. Todos os seus coeficientes são significativos, além de apresentarem critérios de AIC e SBC menores do que os dos modelos $\mathrm{ARCH}$, o que indica que eles são os mais adequados para modelagem da variância das séries. As Tabelas 11 e 12 apresentam os modelos $\operatorname{TARCH}(1,1)$ para as taxas de câmbio à vista e futura.

Tabela 11 - Equação da variância da série de taxa de câmbio à vista na primeira diferença (modelo TARCH $(1,1)$ )

\begin{tabular}{ccccc}
\hline & Constante & $\varepsilon_{t-1}^{2}$ & $\varepsilon_{t-1}^{2} d$ & $\sigma_{t-1}^{2}$ \\
\hline & 0,00001 & 0,249400 & $-0,195613$ & 0,844026 \\
& $(0,0017)$ & $(0,0000)$ & $(0,0011)$ & $(0,0000)$ \\
AIC & $-4,940168$ & & & \\
SBC & $-4,917945$ & & & \\
\hline
\end{tabular}

Nota: Os valores em parênteses são os p-valor.

Fonte: Dados do trabalho. 
Tabela 12 - Equação da variância da série de taxa de câmbio futura na primeira diferença (modelo TARCH $(1,1)$ )

\begin{tabular}{ccccc}
\hline & Constante & $\varepsilon_{t-1}^{2}$ & $\varepsilon_{t-1}^{2} d$ & $\sigma_{t-1}^{2}$ \\
\hline & 0,00005 & 0,364629 & $-0,081437$ & 0,669500 \\
& $(0,0147)$ & $(0,0000)$ & $(0,4259)$ & $(0,0000)$ \\
AIC & $-4,483278$ & & & \\
SBC & $-4,453079$ & & & \\
\hline
\end{tabular}

Nota: Os valores em parênteses são os p-valor.

Fonte: Dados do trabalho.

Assim como nos modelos GARCH, os modelos TARCH apresentam todos os seus coeficientes significativos, à exceção do coeficiente que indicaria a assimetria para a série de taxa de câmbio futura, o que demonstra que choques positivos e negativos exercem influências iguais nesse mercado sobre a variância da série. Além disso, apresentam também menores valores para os critérios de AIC e de SBC do que os modelos $\mathrm{ARCH}$.

Pode-se verificar que os coeficientes de persistência de volatilidade, dados pela soma dos coeficientes $\sum \alpha_{i}+\sum \beta_{i}$ para os modelos $\operatorname{GARCH}(1,1)$ e pela soma dos coeficientes $\sum \alpha_{i}+\sum \beta_{i}+\gamma / 2$ para os modelos $\operatorname{TARCH}(1,1)$, são praticamente iguais a 1 , indicando que choques na volatilidade perduram por um longo período de tempo nas séries em questão. A significância do parâmetro que indica a assimetria diz que choques negativos levam a uma volatilidade maior na série de taxa de câmbio à vista na primeira diferença do que choques positivos. Isso se deve ao fato de se ter tomado o valor zero para erros positivos e o valor 1 para erros negativos. Assim, pode-se afirmar que as informações correntes sobre a volatilidade permanecerão sendo importantes para explicar a variância condicional das taxas de câmbio à vista e futura por um período de tempo relativamente longo, o que indica elevado grau de risco no mercado de câmbio à vista e futuro. 
As previsões para a taxa de câmbio à vista são realizadas por meio do modelo $\mathrm{TACH}(1,1)$, já que se detectou assimetria para esta série. Para a série de taxa de câmbio futura, as previsões são com o modelo GARCH(1,1). A qualidade de ajustamento do modelo pode ser confirmada por meio da análise das estatísticas contidas na Tabela 13. Percebe-se, de acordo com as estatísticas que avaliam a eficiência da previsão, que os modelos ajustados são bons modelos de previsão. Na Tabela 13, (i) e (ii) dependem da escala da variável e devem ser usados como média relativa; (iii) e (iv) independem da escala, sendo que (iv) varia entre $0 \mathrm{e}$ 1, em que o valor zero indica um ajustamento perfeito; (v) e (vi) mostram, respectivamente, a que distância a média e variância da previsão estão da média da série real; e (vii) apresenta o restante dos erros nãosistemáticos da previsão. Note que (v), (vi) e (vii) somam 1, de modo que, se a previsão for boa, (v) e (vi) devem ser próximos de zero, fazendo com que (vii) se aproxime de 1.

Tabela 13 - Valor das estatísticas que avaliam a eficiência de previsão do modelo

\begin{tabular}{lcc}
\hline \multicolumn{1}{c}{ Estatísticas } & $\begin{array}{c}\text { Valor da estatística para } \\
\text { previsão da taxa de } \\
\text { câmbio à vista para as 30 } \\
\text { últimas observações }\end{array}$ & $\begin{array}{c}\text { Valor da estatística } \\
\text { para previsão da taxa } \\
\text { de câmbio futura para } \\
\text { as 30 últimas } \\
\text { observações }\end{array}$ \\
\hline $\begin{array}{l}\text { (i) Raiz do Erro Médio ao } \\
\text { Quadrado }\end{array}$ & 0,018979 & 0,020369 \\
(ii) Média Absoluta do Erro & 0,015883 & 0,016937 \\
(iii) Percentual da Média & 0,716239 & 0,759484 \\
$\begin{array}{l}\text { Absoluta do Erro } \\
\text { (iv) Coeficiente de Desigualdade }\end{array}$ & 0,004284 & 0,004571 \\
de Theil & 0,005970 & 0,001439 \\
(v) Proporção de Viés & 0,008858 & 0,003136 \\
(vi) Proporção de Variância & 0,985173 & 0,995365 \\
(vii) Proporção de Covariância &
\end{tabular}

Fonte: Dados do trabalho. 
As estatísticas apresentadas na Tabela 13 são mais adequadas para comparar modelos de previsão; contudo, permitem tirar algumas conclusões sobre a eficiência da previsão dos modelos estimados. Os valores de (i), (ii) e (iii) são bem pequenos, assim como o de (iv), o que indica que os modelos apresentam um ajustamento "quase perfeito". Na mesma tabela, (v) e (vi) apresentaram valores muito próximos de 0; e (vii) apresentou valor próximo de 1 , indicando uma concentração em (vii), o que equivale a dizer que a previsão é de boa qualidade, ou seja, na média, 99\% dos erros de previsão se devem a erros não-sistemáticos (erros de covariância). O que poderia fazer com que o modelo cometesse erros sistemáticos no momento de prever as taxas de câmbio à vista $\mathrm{e}$ futura seriam as proporções de viés e de variância, que, somados, se mostram pouco significativos, se aproximando de $1 \%$ do total de erros, na média.

A Tabela 14 mostra os valores observados e previstos para o período de 3/11/2005 a 15/12/2005. Observe que os erros de previsão, em ambas as séries, variam entre $0,02 \%$ e $1,8 \%$, indicando que os modelos possuem grande poder de predição. Visto que os dados referentes às taxas de câmbio possuem alta volatilidade, como comprovado no próprio estudo, obter modelos que apresentem erros dessa magnitude é de suma importância. Os modelos, além disso, captam uma provável estabilidade apresentada nos mercados de câmbio, para o período analisado. 
Francisco Carlo da Cunha Cassuce,

Carlos André da Silva Muller \& Antônio Carvalho Campos

Tabela 14 - Previsão para taxa de câmbio nominal para o período de $3 / 11 / 2005$ a $15 / 12 / 2005$

\begin{tabular}{|c|c|c|c|c|c|c|}
\hline Período & $\begin{array}{c}\text { Valores } \\
\text { observados } \\
\text { para câmbio à } \\
\text { vista }\end{array}$ & $\begin{array}{c}\text { Valores } \\
\text { previstos } \\
\text { (método } \\
\text { Estático) para } \\
\text { câmbio à vista }\end{array}$ & $\begin{array}{l}\text { Erro* }(\%) \text { do } \\
\text { câmbio à vista }\end{array}$ & $\begin{array}{c}\text { Valores } \\
\text { observados } \\
\text { para câmbio } \\
\text { futuro }\end{array}$ & $\begin{array}{c}\text { Valores } \\
\text { previstos } \\
\text { (método } \\
\text { Estático) para } \\
\text { câmbio futuro }\end{array}$ & $\begin{array}{l}\text { Erro }{ }^{*}(\%) \text { do } \\
\text { câmbio futuro }\end{array}$ \\
\hline $03 / 11 / 2005$ & 2,2328 & 2,251847 & 0,853073 & 2,251461 & 2,247364 & $-0,18195$ \\
\hline $04 / 11 / 2005$ & 2,2223 & 2,229379 & 0,318558 & 2,242951 & 2,245088 & 0,095257 \\
\hline $07 / 11 / 2005$ & 2,2005 & 2,222352 & 0,993062 & 2,220543 & 2,216664 & $-0,17468$ \\
\hline $08 / 11 / 2005$ & 2,2024 & 2,197054 & $-0,24274$ & 2,220418 & 2,223334 & 0,131316 \\
\hline $09 / 11 / 2005$ & 2,1709 & 2,204276 & 1,53745 & 2,187254 & 2,181617 & $-0,25771$ \\
\hline $10 / 11 / 2005$ & 2,1749 & 2,165067 & $-0,45212$ & 2,188995 & 2,193378 & 0,200238 \\
\hline $11 / 11 / 2005$ & 2,1625 & 2,178354 & 0,733113 & 2,176549 & 2,172172 & $-0,2011$ \\
\hline $14 / 11 / 2005$ & 2,1982 & 2,158617 & $-1,80072$ & 2,210306 & 2,217358 & 0,319044 \\
\hline $16 / 11 / 2005$ & 2,1966 & 2,205245 & 0,393558 & 2,208998 & 2,203952 & $-0,22845$ \\
\hline $17 / 11 / 2005$ & 2,1858 & 2,192382 & 0,301142 & 2,198007 & 2,200547 & 0,115569 \\
\hline $18 / 11 / 2005$ & 2,2179 & 2,186233 & $-1,42781$ & 2,226564 & 2,228081 & 0,068115 \\
\hline $21 / 11 / 2005$ & 2,2173 & 2,222122 & 0,217484 & 2,225039 & 2,223934 & $-0,04968$ \\
\hline $22 / 11 / 2005$ & 2,2503 & 2,214731 & $-1,58065$ & 2,256893 & 2,261389 & 0,19921 \\
\hline $23 / 11 / 2005$ & 2,2372 & 2,256251 & 0,851571 & 2,242076 & 2,237354 & $-0,21062$ \\
\hline $24 / 11 / 2005$ & 2,2362 & 2,231885 & $-0,19296$ & 2,241488 & 2,244956 & 0,154735 \\
\hline $25 / 11 / 2005$ & 2,2321 & 2,238648 & 0,29334 & 2,236787 & 2,233929 & $-0,12776$ \\
\hline $28 / 11 / 2005$ & 2,2086 & 2,229964 & 0,967304 & 2,212667 & 2,212175 & $-0,02224$ \\
\hline $29 / 11 / 2005$ & 2,1972 & 2,20607 & 0,403714 & 2,198016 & 2,196885 & $-0,05144$ \\
\hline $30 / 11 / 2005$ & 2,2062 & 2,196647 & $-0,43302$ & 2,201557 & 2,202913 & 0,061592 \\
\hline $01 / 12 / 2005$ & 2,2169 & 2,207574 & $-0,42069$ & 2,239837 & 2,243286 & 0,154005 \\
\hline $02 / 12 / 2005$ & 2,2053 & 2,217496 & 0,553053 & 2,22728 & 2,223559 & $-0,16704$ \\
\hline $05 / 12 / 2005$ & 2,196 & 2,203054 & 0,321213 & 2,217986 & 2,219766 & 0,080239 \\
\hline $06 / 12 / 2005$ & 2,1799 & 2,195602 & 0,720331 & 2,197905 & 2,194541 & $-0,15304$ \\
\hline $07 / 12 / 2005$ & 2,1792 & 2,177526 & $-0,07683$ & 2,193151 & 2,195181 & 0,092579 \\
\hline $08 / 12 / 2005$ & 2,2119 & 2,180126 & $-1,43648$ & 2,225347 & 2,227635 & 0,102804 \\
\hline $09 / 12 / 2005$ & 2,2438 & 2,215947 & $-1,24133$ & 2,259296 & 2,261595 & 0,101753 \\
\hline $12 / 12 / 2005$ & 2,2626 & 2,24607 & $-0,7306$ & 2,276319 & 2,276722 & 0,017704 \\
\hline $13 / 12 / 2005$ & 2,2557 & 2,263903 & 0,363639 & 2,267626 & 2,266519 & $-0,04883$ \\
\hline $14 / 12 / 2005$ & 2,2771 & 2,253764 & $-1,0248$ & 2,289104 & 2,292444 & 0,145904 \\
\hline $15 / 12 / 2005$ & 2,2949 & 2,28102 & $-0,60481$ & 2,304981 & 2,30451 & $-0,02041$ \\
\hline
\end{tabular}

Fonte: Dados do trabalho.

A Figura 10 mostra os valores previstos das taxas de câmbio à vista e futura um mês à frente. Nesse caso, as 30 últimas observações, ou seja, o período de 3/11/2005 a 15/12/2005, estão incorporadas ao modelo. As condições propícias para praticar arbitragens são identificadas tomandose como foco os períodos de prazo-limite para negociação, ou seja, o último dia útil do mês anterior ao mês do contrato. Assim, duas datas apresentam-se como possíveis: 29/12/2005 e 31/1/2006. A taxa de câmbio futura apresenta leve tendência de alta, fechando em 29/12/2005 a $\mathrm{R} \$ 2,3055$, e a taxa de câmbio à vista fecha a $\mathrm{R} \$ 2,2953$. Para a data de $31 / 1 / 2006$, a taxa de câmbio futura fecharia a $R \$ 2,3076$, ao passo que a taxa de câmbio à vista tende a cair, fechando em $\mathrm{R} \$ 2,2898$. 


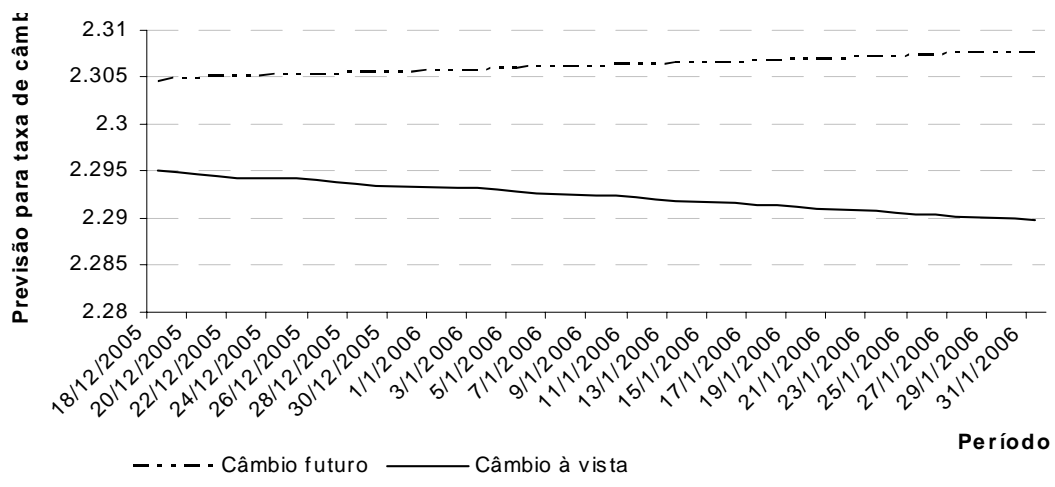

Figura 10 - Previsão para taxas de câmbio à vista e futura para o período de 18/12/2005 a 31/1/2006.

Fonte: Dados do trabalho.

Tomando o valor de US $\$ 50.000,00$ para cada contrato de câmbio futuro, ter-se-ia para a primeira data de fechamento, 29/12/2005, uma diferença de aproximadamente $\mathrm{R} \$ 0,0102$ por dólar. Nesse caso, há margem para prática de arbitragem no mercado de câmbio, desde que os custos de transações nesse mercado não excedam $\mathrm{R} \$ 510,00$ por contrato, o que equivaleria ao lucro do arbitrador caso os custos operacionais fossem zero. Considerando a taxa operacional de $0,4 \%$ do valor do contrato, o custo operacional de cada contrato seria de US $\$ 200,00$. Sendo a diferença entre as taxas igual a US $\$ 222,19$, a operação de arbitragem gera um lucro de US $\$ 22,19$ por contrato negociado, ao considerar a primeira data de vencimento e a taxa de câmbio à vista prevista para essa data.

A segunda data de fechamento, 31/1/2006, apresenta diferença de aproximadamente $\mathrm{R} \$ 0,0178$ por dólar. A partir desse resultado, a prática de arbitragem é possível, desde que os custos de transação no mercado não ultrapassem a quantia de $\mathrm{R} \$ 890,00$ por contrato negociado. Admitindo a taxa de $0,4 \%$ do valor da operação, o lucro obtido com a arbitragem, descontado o custo operacional, seria ainda maior, ou seja, de aproximadamente US $\$ 188,68$ por contrato, considerando a taxa de câmbio 
Francisco Carlo da Cunha Cassuce,

Carlos André da Silva Muller \& Antônio Carvalho Campos

à vista prevista para essa data. Contudo, deve-se salientar que a prática de arbitragem para a segunda data só seria possível caso a possibilidade de obter ganhos com essa atividade não tivesse sido identificada anteriormente. Caso contrário, a prática de arbitragem na primeira data elimina as possibilidades de lucro na segunda data.

Verifica-se leve tendência de alta para a taxa de câmbio futura e de queda para a taxa de câmbio à vista. Isso tende a elevar o lucro com a prática de arbitragem. No entanto, teoricamente, o mercado tende a corrigir essas desigualdades de modo a gerar algum mecanismo capaz de forçar a convergência de ambas as taxas, à medida que as operações de arbitragem forem sendo praticadas. A tendência é de que a taxa de câmbio futura caia e a taxa de câmbio à vista aumente, convergindo ambas para um único valor e, assim, eliminando a possibilidade de arbitragem, à medida que os contratos forem sendo liquidados.

\section{Conclusões}

Os resultados mostraram que os mercados de câmbio à vista e futuro são altamente voláteis; o primeiro apresenta assimetria, sendo, por isso, mais afetado por impactos negativos, o que não ocorre com o mercado futuro de câmbio. A análise da volatilidade revelou que a influência de choques sobre as variâncias de ambas as taxas de câmbio perdura por um longo período de tempo, indicando elevado grau de risco em ambos os mercados.

A partir de modelos de previsão bem ajustados, estimou-se a taxa de câmbio para os períodos de 18/12/2005 a 31/1/2006. Considerando uma taxa operacional de $0,4 \%$ no mercado futuro de câmbio, a prática de arbitragem foi lucrativa nas duas datas de vencimento do contrato, que compreendem o período previsto. Além disso, observou-se divergência entre as taxas de câmbio futuro e à vista, com a primeira apresentando leve tendência de alta e a segunda de queda, o que aumentaria os lucros com a prática da arbitragem. 
Finalmente, o mercado de câmbio tendeu a eliminar a possibilidade de geração de lucros com a arbitragem, uma vez que, à medida que os contratos vão sendo liquidados, o câmbio futuro tende a cair e a taxa de câmbio à vista tende a aumentar, de forma que ambas convirjam. $\mathrm{O}$ comportamento das séries em nível indica que, por alguns momentos no tempo, elas se distanciam, mesmo que por pouco: ora a taxa de câmbio à vista é mais alta, ora a taxa de câmbio futura é maior. Quando esse fenômeno estiver ocorrendo, e em um período em que a taxa de câmbio futura se coloca acima da taxa de câmbio à vista, há a caracterização da possibilidade de ganhos com arbitragem.

\section{Referências}

AMIM, M.M. A ação especulativa dos fundos hedge e de commodities nos mercados futuros de cacau. 2002. Disponível em: $\langle$ www.cac-php.unioeste.br/revistas/gepec/download.php?id=5 >. Acesso em: 12 de agosto de 2006.

BILLI, M. e VIEIRA, F. BM\&F Incha e Favorece Maior Volatilidade. 2005. Disponível em <www1.folha.uol.com.br/folha/ dinheiro>. Acesso em 10 de outubro de 2005.

BM\&F. Síntese Agropecuária. 2006. Disponível em: <http:// w w w.agrolink.com.br/cotacoes/arquivos / 17820061047011379Sintese280.pdf\#search=\%22arbitragem\%20\%22 mercado\%20futuro\%22\%22>. Acesso em 12 de agosto de 2006.

BM\&F. Séries de câmbio a vista e futuro para compra. 2006. Disponível em: 〈www.ipeadata.gov.br〉. Acesso em: 20 de outubro de 2005.

ENDERS, W. Applied econometric time series. New York: Jonh Wiley, 1995. 433p. 
Francisco Carlo da Cunha Cassuce,

Carlos André da Silva Muller \& Antônio Carvalho Campos

GARCIA, M.G.P. A Macroeconomia do Dólar Futuro. 1997. Disponível em: <www.econ.puc-rio.br/Mgarcia/Artigos/Macrometrica/ !MACROMT.RIC/macdol.pdf >. Acesso em 15 de agosto de 2006.

GARCIA, M.G.P.; URBAN, F. O mercado interbancário de câmbio no Brasil. 2006. Disponível em: <www.econ.puc-rio.br/Mgarcia/Papers/ Garcia\&Urban040325.pdf>. Acesso em: 14 de agosto de 2006.

HULL, J. Introdução aos mercados futuros e de opções. 2. ed. São Paulo: BM\&F, 1996. 448p.

ISARD, P. Exchange rate economics. Cambridge: Cambridge University Press, 1995. 275p.

KRUGMAN, P.R.; OBSTFELD, M. Economia internacional: teoria e política. São Paulo: Makron Books, 2005. 558 p.

LAMOUNIER, W.M. Comportamento dos preços no mercado "spot" de café do Brasil: análise nos domínios do tempo e da freqüência. $207 \mathrm{f}$. Tese (Doutorado em Economia Aplicada)Universidade Federal de Viçosa, Viçosa, MG, 2001.

MARK, N.C. International macroeconomics and finance: theory and econometric methods. Malden, Massachusetts: Blackwell Publishers, 2001.283p.

MIGUEL, P.P. Paridade de juros, fluxo de capitais e eficiência do mercado de câmbio do Brasil: evidências dos anos 90. 2001. Disponível em: <www.econ.fea.usp.br/novo site/ pos-graduacao/ defesas dissert.html>. Acesso em: 10 de outubro de 2005.

MOL, A. L. R.; CASTRO JUNIOR, L. G.; SATADI, T.; FIGEUIREDO, D.F. Assimetria na volatilidade dos retornos de derivativos de café. 2003. Disponível em: <www.bmf.com.br/pages/educacional1/ publicacoes/resenha1/PDFs/res157/artigostecnicos2.pdf > Acesso em: 10 de outubro de 2005. 
QMS. Eviews user's guide. Irvine, CA, USA: Quantitative Micro Software, LLc, 2004.

SILVA NETO, L. A. Derivativos: definições, emprego e risco. 2. ed. São Paulo: Atlas, 1998. 298p.

TEWELES, R. J.; JONES, F. J. The futures game: who wins, who loses, \& why. $3^{\text {th }}$ edition. New York : McGraw-Hill, 1998. 676p.

Abstract - The objective of this work is to determine the presence of volatility in the spot and futures exchange rates, detecting, thus, the presence of risk. Identified the volatility, it is looked for shaping it through the construction of models capable to forecast the behavior of the spot and futures exchange rates. The GARCH and TARCH models had been used to shape the volatility of the exchange rates. Gotten the estimates, it is verified existence of convergence of these rates in the date of the expirations of future contracts, identifying, thus, the chance to get profits with arbitrage. The results had shown more that the spot and futures exchange rates are very volatile and the spot exchange market presents asymmetry, being affected for negative impacts. The volatility analysis also indicates that the shocks in these rates last for a long period of time. Finally, it is detected possibility to get profits with arbitrage in the market of Brazilian exchange.

Keywords: arbitrage, spot exchange rate, futures exchange rate, volatility. 